hacia el fin de su libro, echando las bases para una discusión que sería, muy fructífero continuar.

"Libro extremadamente importante", ha dicho con razón Alfredo Roggiano. En efecto: por su elegante arquitectura; por la solidez de su argumentación, siempre apoyada en un fuerte conocimiento histórico-factual; por la síntesis diáfana y compleja que nos propone de los temas de la conquista, Discursos narrativos de la conquista es una contribución magistral. Juntando sus gavillas, la cosecha es abundante. Tenemos, en haz sucesivo, una impecable exposición sobre Colón, una interpretación en profundidad de Cortés, páginas lúcidas y luminosas acerca de Alvar Núñez y de Aguirre y una poderosa revaloración del más alto poema épico del Siglo de Oro. En el nuevo y sesquicentenario campo de los estudios de literatura colonial, este libro se une a los trabajos pioneros de Raquel Chang-Rodríguez, a la summa de sabiduría sorjuanina representada por Georgina Sabat de Rivers, y a las recientes contribuciones de Rolena Adorno. Está entre lo mejor producido por estudiosas y estudiosos del tema en el país.

\title{
University of California,
}

San Diego, La Jolla

JAIME CONCHA

ADOLFO PRIETO: El discurso criollista en la formación de la Argentina moderna.

Buenos Aires: Editorial Sudamericana, 1988.

Ahora que tal vez demasiados trabajos críticos parecen destinados a probar sobre todo la agudeza intelectual de sus autores y el brillo de su erudición teórica, el libro de Adolfo Prieto sobre el criollismo argentino de fines del XIX y comienzos del XX es francamente aleccionador y estimulante. Y lo es, primero, por razones muy simples: surge de una investigación seria, detenida y minuciosa, abarcadora de una amplia gama de fuentes primarias; maneja con solvencia y discreción el aparato teórico que es necesario para resolver los problemas concretos de su materia, sin exhibirlo ni excederse; respeta al lector porque hace explícita su argumentación, la verifica y propone conclusiones orgánicas, todo ello con un lenguaje nítido y pulcro; y finalmente, para decir algo tan obvio como insólito, produce nuevos conocimientos sobre una materia específica y en diálogo con la tradición crítica pertinente. Por supuesto, resaltar como mérito lo que debería ser condición del trabajo crítico revela mis temores frente al estado actual del hispanoamericanismo como conjunto, pero además apunta al hecho de que esas condiciones, como se verá luego, Prieto las satisface y sobrepasa largamente. 
El discurso criollista en la formación de la Argentina moderna está basado sobre la disciplina que primero cultivó Prieto: la sociologia de la literatura, o más específicamente del público literario, que inicialmente tuvo una cierta vocación empirista, ahora superada con felicidad. Esto explica que el capítulo primero determine la formación de los "campos de lectura" en el periodo comprendido entre 1880 y 1910 a partir de un análisis de los resultados de las campañas de alfabetización, de la política de educación popular y del consiguiente crecimiento de la prensa periódica, análisis que es de inmediato relacionado con datos que provienen de la demografía (inmigración europea, desplazamientos del campo a la ciudad, etc.), todo lo cual conduce a la formación de un nuevo público literario, que no desplaza al antiguo, el de la elite letrada, pero lo acosa con sus nuevos comportamientos y su masividad.

Prieto examina también la manera cómo las espectativas de ese nuevo público son satisfechas por un grupo asimismo nuevo de productores de literatura y el modo cómo se enlazan a través de circuitos de circulación antes inexistentes. En general, se trata de letrados nuevos, poco adiestrados en el manejo de los códigos cultos pero con relaciones con la escritura periodística muy concientes de que no pueden competir en términos de excelencia artística con los maestros de la literatura oficial, aunque exhiben persistentemente — con ambigüedad que no deja de ser irónica- la magnitud de una audiencia que ningún autor consagrado puede ni siquiera pretender. Se trata del primer grupo profesional de escritores.

Aquí caben dos comentarios. El primero tiene que ver con la secuencialidad de los hechos, que sospecho algo más entreverada, por cuanto las necesidades del público generan los mecanismos de su satisfacción, pero también, a la inversa, la circulación de nuevos textos suscita el apetito de lectores recién conquistados, y que conquistan a otros, aspecto que Prieto insinúa pero no desarrolla en todas sus implicancias. El segundo es una reflexión marginal: ¿cómo explicar que la profesionalización del escritor, signo inequívoco de modemidad, aparezca primero en los productores menos modernos, con evidentes raíces tradicionales, y sólo mucho después en los que estaban en la cresta de la ola de la modernidad literaria? Libros como el de Prieto tienen la innegable virtud de suscitar dudas y preguntas cuya aparente nimiedad desemboca en cuestiones fundamentales. Por ejemplo: ¿no será que la modernidad latinoamericana es otra modernidad, ajena a la "puesta al día" de los imaginarios y formas culturales con respecto a unos modelos metropolitanos que - desde esta perspectiva- no implicarían ni arcaísmo ni modernidad?

Prieto se esmera en diseñar y explicar cómo el "aire de extranjería y cosmopolitismo" de la Argentina de entonces, sobre todo en sus espacios urbanos, pudo reconocerse en una literatura criollista, y se preocupa sobre todo por rastrear las 
relaciones entre esta literatura con la literatura culta, relaciones que son tanto de contraste y exclusión como de interacciones muy ambiguas. A este efecto prefiere trabajar más que sobre textos específicos, aunque una y otra vez acude a ellos, sobre figuras claves de la galería de símbolos criollos: Martín Fierro, Moreira, Santos Vega. En el capítulo tal vez más logrado del libro, y también incitante para el lector interesado en los cruces socio-culturales que tejen la literatura latinoamericana, Adolfo Prieto interpreta la "red textual" y los "deslizamientos" de las lecturas (y de las escrituras) relativos a esos paradigmas criollos. Los análisis acerca del "moreirismo" y el "antimoreirismo", enriquecidos con informes sobre otras figuraciones sociales de ese símbolo, desde una ópera en italiano hasta los disfraces carnavalescos, como también los concernientes a la reconstrucción culta de Santos Vega, tienen una espléndida capacidad esclarecedora: dan razón de la conflictividad de la cultura argentina de la época, que en el fondo reproduce una muy aguda beligerancia social, pero también iluminan situaciones de mucho mayor alcance. Imagino que gauchesca y criollismo bien podrían comprenderse dentro del marco de lo que Angel Rama llamó "literaturas transculturales" y en relación con lo que alguna vez denominé, con respecto a otra materia, "literaturas heterogéneas".

En relación a este asunto, Prieto emplea el criterio de Chevalier. Señala asíque la literatura criollista (en general, la popular) es una forma de civilización que afecta a la conciencia y a los comportamientos sociales de vastos sectores de las clases dominadas ("como forma de civilización la literatura popular de signo criollista proveyó símbolos de identificación y afectó considerablemente las costumbres del segmento más extendido de la estructura social" p. 145), mientras que esa misma literatura para otros grupos sociales, definidos algo vagamente como perteneciente a la burguesía, no fue más que un "objeto de cultura" $\mathrm{o}-$ como se señala luego- un "objeto de observación" (p. 157). Prieto anota que la magnitud y el sentido de la distancia que separa al objeto observado del observador tiene, en este caso, múltiples variantes, con sus zonas de permeabilidad y sus zonas de rechazo, pero al mismo tiempo establece sagazmente que para la conciencia letrada el criollismo podía causar, a la vez, fascinación, perplejidad, exaltación y condena.

Sin duda es así, y Prieto lo demuestra con solvencia, pero es probable que el criollismo argentino remita a ambigüedades y contradicciones aún más agudas, relativas tanto a la extrema heterogeneidad de su modo de producción como a la dramática constitución transcultural de su sujeto emisor. Es arriesgado ubicar al criollismo, y a la gauchesca, en el discurso que abren las crónicas, se despliega en el negrismo, el indigenismo, la novela del nordeste brasileño, y reaparece en el realismo mágico, en sectores de la poesía conversacional o en el testimonio, pero 
investigaciones tan cuidadosas y tan perspicaces como la de Prieto dan pie para intuir que un segmento muy apreciable de la literatura latinoamericana sólo se explica por su inestable instalación en las intersecciones de varios modos de organización social y de muy desiguales — hasta incompatibles- códigos culturales.

Universidad de San Marcos
University of Pittsburgh
ANTONIO CORNEJO POLAR

HENSLEY WOODBRIDGE Y DAVID ZUBATSKY: Pablo Neruda: An Annotated Bibliography of Biographical and Critical Studies: La más completa Bibliografia sobre la obra de Neruda. New York: Garland Publication, 1988.

Más de cincuenta bibliografías se han publicado sobre la voluminosa obra de Pablo Neruda desde el año 1936 en que la Revista Hispánica Moderna, en tres páginas, publicó la primera lista de obras de y sobre el poeta chileno, preparada por Sidonia Rosenbaum. Desde muy temprano la actividad literaria de Neruda despertó el interés de los lectores hispánicos y algunos de entre ellos afrontaron la voluntaria tarea de tomar nota de todo lo que se iba publicando relativo a ese autor.

El primero de estos bibliógrafos persistentes fue, en Chile, el Padre Alfonso Escudero, quien presentó en 1964, en la revista Mapocho, las "Fuentes para el conocimiento de Neruda". Las primeras ediciones de las Obras Completas, publicadas por Losada, traen esta bibliografía, la que ha ido aumentando en cada nueva edición, a cargo de un antiguo y fiel crítico nerudiano: Hernán Loyola.

La primera publicación de una bibliografía sobre este autor en forma de libro autónomo la realizó Jorge Horacio Becco (Buenos Aires, Casa Pardo) en 1975. Son 261 páginas y 1057 entradas bibliográficas en las cuales predominan referencias a la crítica hecha en Chile y Argentina y se limita a la escrita en idioma español. Los siguientes aportes importantes en esta materia se cumplen en los Estados Unidos, gracias a los esfuerzos de varias personas, entre ellos, Enrico Mario Santí, Angel Flores, y David William Foster.

En los años setenta comienzan a aparecer también bibliografías dedicadas exclusivamente a la obra y crítica nerudiana en otras lenguas, dando cuenta de las respectivas traducciones. Entre ellas se destacan las de Bonnie Beckett sobre la recepción en lengua alemana, las de Giuseppe Bellini y de Gabriele Morelli en italiano, la de Esperanza Figueroa en inglés, la de Ingemann Larsen en danés y la de Emil Volek en idiomas de los países socialistas de Europa. 